\title{
A INCLUSÃO DIGITAL NA ESCOLA PARA A ERRADICAÇÃO DO ANALFABETISMO TECNOLÓGICO
}

MELO, Angela Fernandes ${ }^{1}$

\begin{abstract}
RESUMO
O presente trabalho busca discorrer sobre a importância da Inclusão Digital dentro das escolas, criando oportunidades de uma interação entre alunos, professores e comunidade. $E$ tem como objetivo geral analisar a forma de inclusão digital empregada nas instituições de ensino, envolvendo, como principal condição, o acesso ao exercício da cidadania dentro da sociedade moderna. $O$ interesse pelo tema justifica-se pela preocupação de a exclusão digital ser a causa maior do analfabetismo tecnológico, ampliando as desigualdades, o que é uma violência velada. Trata-se de um estudo teórico reflexivo bibliográfico de cunho qualitativo, cuja escolha dos autores deve-se à natureza de suas experiências que falam sobre o uso da internet na educação como "interação humana", a possível redução da massa de analfabetismo tecnológico e inserção dos sujeitos em programas que visam a inclusão digital nas escolas. Sua finalidade é abordar a inclusão digital, tendo como princípio a conscientização de que não se trata exclusivamente de disponibilizar computadores para o uso da comunidade, mas depende da forma como essa tecnologia é empregada e vem a atender às necessidades dessas pessoas ao acesso à informação e ao conhecimento dessa ferramenta. A inclusão digital ganha significação ao ser introduzida num ambiente escolar com perspectivas de novas oportunidades que visam melhorar a educação tornando-a de qualidade e para todos.
\end{abstract}

PaLAVRAS-CHAVE: Inclusão Digital - Instituição Escolar - Analfabetismo Tecnológico.

\section{ABSTRACT}

This paper seeks to discuss the importance of Digital inclusion within the schools, creating opportunities of an interaction between students, teachers and the community. And aims to analyze the General form of digital inclusion employed in educational institutions, involving main condition access to the exercise of citizenship in modern society. The interest in the subject is justified by the concern of digital divide being the greater cause of technological illiteracy widening inequalities, which is a veiled violence. It is a theoretical study of bibliographic quality reflective, whose choice of authors is due to the nature of their experiences to talk about using the internet in education as "human interaction", the possible reduction in the mass of technological illiteracy and integration of subject in programs aimed at the digital inclusion in schools. Its purpose is to address the digital inclusion, with the principle of awareness that this is not solely to provide computers for use by the community, but de-

\footnotetext{
1 Professora do Instituto de Aplicação Fernando Rodrigues da Silveira (CAp-UERJ). Email: angelafernandes.melo@yahoo.com.br
} 
e-Mosaicos - Revista Multidisciplinar de Ensino, Pesquisa, Extensão e Cultura do Instituto de Aplicação Fernando Rodrigues da Silveira (CAp-UERJ)

V. 5 - N. 10 - DEZEMBRO 2016 - ISSN: 2316-9303

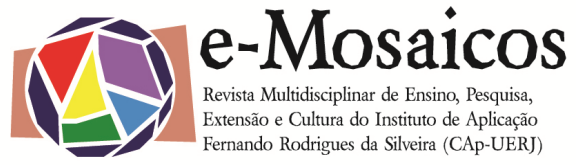

pends on how this technology is employed and will meet the needs of these people to access to information and to knowledge of this tool. Digital inclusion WINS meaning to be introduced in a school environment with prospects for new opportunities to improve education quality and become for all.

KeYWORDS: Digital Inclusion - School Institution - Technological Illiteracy.

\section{INTRODUÇÃO}

Os impactos da tecnologia tiveram um grande aumento nas últimas décadas. A Internet e as redes sociais propiciaram o surgimento de uma nova sociedade, mais aberta a informações e conhecimentos. 0 uso da internet proporcionou uma grande combustão digital e tecnológica. Entrou em vigor a era da inteligência em rede, na qual seres humanos combinam seu cognitivo, conhecimento e criatividade para revoluções na produção de riquezas e desenvolvimento social.

Diante da revolução da informática e do constante uso dessas tecnologias, que são vivenciadas no cotidiano das pessoas, inúmeras vertentes apontam que a educação deve acompanhar e inserir, em seu contexto, esses avanços tecnológicos presentes na sociedade. No artigo 205 da Constituição Federal, está expresso "que a educação é direito de todos e a sua promoção é dever do Estado e da família, em colaboração com a sociedade, dela depende o pleno crescimento da pessoa, o seu preparo para o exercício da cidadania e a consequente qualificação para o trabalho" (BRASIL, 1998).

A inclusão digital é a porta de acesso que transmite a comunicação por meio das Tecnologias de Informação e Comunicação. Designam-se por inclusão digital alguns projetos e ações que facilitam o acesso das pessoas a essas tecnologias. Dessa forma, essa camada da população também pode ter acesso aos conteúdos disponibilizados pela internet, além de poder produzir conhecimento.
O analfabetismo tecnológico referese a uma não competência para "ler" o mundo digital e mexer com a tecnologia moderna, principalmente com relação ao domínio dos conteúdos da informática, como planilhas, internet, editor de textos etc. A causa desse analfabetismo é associada à "exclusão digital", denunciada em todo o mundo como a forma mais moderna de violência aos direitos de cidadão e modalidade sutil de manutenção e ampliação das desigualdades.

A Lei de Diretrizes e Bases da Educação Nacional (1996) preconiza a necessidade da "alfabetização digital" em todos os níveis de ensino, do fundamental ao superior, mas, de acordo com o Ministério da Educação (MEC), o analfabetismo é, sem dúvida, o maior desafio a ser enfrentado pelo Estado para a consolidação de uma sociedade da informação no Brasil.

$O$ interesse pelo tema justifica-se pela preocupação com o fato de haver escolas que possuem laboratórios de informática e ainda não utilizam este recurso, ausência de políticas de formação ampla e uma falta de investimentos nas competências dos professores. A exclusão digital é a causa maior do analfabetismo tecnológico que, de forma sutil, amplia as desigualdades sociais.

Para Weiss (2009, p. 132), o uso da informática tem se revelado como um precioso instrumento, não só nos diagnósticos, mas também no tratamento das dificuldades de aprendizagem escolar, auxiliando no desenvolvimento do processo cognitivo, com a concentração de atenção, reforço da memória, desenvolvimento 
do pensamento lógico, rapidez de raciocínio, percepção gestativa do problema, buscando assim uma maior facilidade na tomada de consciência de seu próprio pensar e de seus processos e estratégias.

A proposta do trabalho é pesquisar e procurar entender como erradicar o analfabetismo tecnológico e incluir digitalmente os cidadãos que se encontram à margem da sociedade em rede, trazendo para dentro da escola a importância da inclusão social, que tem como base propor o acesso dos indivíduos às formas de produção autônomas, possibilitadas pelas novas tecnologias.

Tendo em vista as questões abordadas acima, o tema de pesquisa escolhido visa analisar a inclusão digital dentro das instituições escolares e nas comunidades ao redor, enfatizando a necessidade de se erradicar o analfabetismo tecnológico e incluir recursos tecnológicos, partindo do princípio de que não se trata apenas de uma questão simplista que possa ser resolvida com a disponibilização de computadores dentro das escolas ou em pontos estratégicos da cidade, não significando somente uma questão de conexão física, mas da observação de como esse acesso à tecnologia poderá suplementar às indigências da sociedade, quando se trata de acesso à informação.

Dentre os objetivos do trabalho, destaca-se a importância de investigar a aproximação dos professores e dos alunos do universo da informática e a promoção da inclusão digital nas instituições de ensino. E como objetivos específicos, refletir sobre as formas propostas para a erradicação do analfabetismo no campo da tecnologia dentro da escola; ressaltar as possibilidades e o direito à igualdade de oportunidades, a fim de se colaborar para resgatar os excluídos em plena era da informática digital; abordar de forma objetiva e significativa o valor da inclusão digital dentro da escola, através dos programas e políticas públicas.
Trata-se de uma pesquisa com fundamentação teórica de natureza bibliográfica. A metodologia utilizada é de cunho qualitativo e se constitui de um levantamento de dados bibliográficos, referente ao tema, e, paralelo a isso, a verificação das práxis de sala de aula.

\section{1 - INCLUSÃo SOCIAL Versus ExCLUSÃo DIGITAL}

A internet como mídia que mais cresce nos últimos anos e tende a ser a mídia mais popular em médio prazo, tem uma característica ampla de possibilitar diversos tipos de comunicações e interações entre culturas, de forma bastante enriquecedora. Por meio do computador, podem-se desenvolver simultaneamente várias habilidades, facilitando a formação de indivíduos polivalentes e multifuncionais. Na visão de Tajra (2001, p. 20), com as novas tecnologias da informação e da comunicação (TICs), cabe à escola a responsabilidade de prestar sua grande contribuição na formação de indivíduos proativos para atuarem nas economias do futuro.

No século XXI, temos o desenvolvimento da computação móvel de laptops, palms, celulares, smartphones, que se conecta à globalização através das redes 3G, Wi-Fi, onde têm como recursos interativos de comunicação os blogs, fóruns, chats, software livres, entre outros. Nessa conexão entre computadores móveis, a rede transforma-se em um ambiente generalizado de conexão, tendo uma nova linguagem que dá o suporte dos celulares e demais aparelhos de computação portáteis, mergulhados nas redes wireless que se expandem rapidamente, deixando de fora aqueles que não acompanham esta revolução.

É possível vislumbrar uma disseminação bem grande com os benefícios advindos dessa era tecnológica, onde muitas pessoas que entendem a linguagem 
empregada por ela aprenderam a confiar no acesso virtual para acessar contas bancárias e realizar compras, fazendo com que o mercado virtual obtivesse um crescimento maior que as lojas físicas. Porém, nesse contexto, só se incluem aqueles que dominam a linguagem da informática, e têm acesso a esta tecnologia.

Mudanças de paradigmas tornamse uma constante em nossas vidas. O que prevalecia como verdadeiro é considerado obsoleto em pouco tempo. Formar indivíduos é uma tarefa que não se esgotará mais. O conhecimento é resultado de uma construção e, quanto mais se conhece, maior é a necessidade de continuar construindo. O conhecimento não é uma descoberta que está escondida dentro de um tesouro, que alguns intelectuais após muitas tentativas descobrem onde ele está (TAJRA, 2001).

A inclusão digital é, atualmente, uma questão de cidadania no contexto da sociedade do conhecimento, pois ela traz avanços importantes para a inserção do cidadão no mercado de trabalho, além de abranger a área da educação, auxiliar na produção cultural, melhorar as condições de vida, lazer e trabalho da população. $O$ difundir do uso das tecnologias da informação e da comunicação (TICs) é forte aliado para composição do desenvolvimento social, econômico, político, cultural, ambiental e tecnológico.

Silveira (2005) enfatiza que essa discussão em torno da inclusão digital vem a acarretar uma definição de seu foco, e aponta para três pontos distintos nessa discussão:

A inclusão voltada para a cidadania, no sentido da busca do direito de interagir e do direito de se comunicar por meio das redes; a inclusão voltada para inserir as camadas mais pauperizadas ao mercado de trabalho - neste caso seria uma inclusão com um foco mais tecnicista, de ações que estão voltadas a meros "cursos de informática"; e por último a inclusão voltada à educação, na perspectiva da importância da formação sociocultural dos jovens, na sua formação e orientação diante do dilúvio informacional. Sendo assim, a definição da inclusão digital se dá com a universalização do acesso ao computador conectado à internet, bem como, ao domínio da linguagem básica para manuseá-lo com autonomia (2005, p. 434).

Para Tajra (2001), várias são as escolas bem conceituadas pela formação de indivíduos proativos, conscientes de seus direitos e deveres, tecnicamente bem preparados para a entrada no mercado de trabalho, que se opõem à utilização da informática educativa. Preferem manter a utilização da informática como fim, sem interferências nos conteúdos disciplinares.

A inserção das novas aprendizagens e as interferências tecnológicas no currículo escolar devem ser algo indispensável, mediante a velocidade com a qual o mundo moderno se movimenta ante as inovações tecnológicas. Essa é uma realidade que deve estar inserida no contexto escolar.

\section{1 - A INFORMÁTICA NA EdUCAÇÃO PARA O SÉCULO XXI}

As reflexões e concepções que contribuem para a Educação enfocam que a escolarização, no seu sentido mais amplo, pode, em qualquer nível de ensino, ser traduzida como a educação do corpo e da mente, ser instrumento sensível de compreensão do mundo, de construção de vínculos com outros corpos sensíveis e simbólicos.

Assim, a construção do conhecimento ocorre por meio da interação mediada pelas várias relações e pela mediação feita por outros sujeitos, onde a brincadeira é essencial para o aprendizado, mas 
também o conhecimento tecnológico, pois, estamos na era da informática e surge uma nova forma de comunicação e socialização capaz de interagir e estimular a escrita, a leitura, a curiosidade e desenvolver a autonomia, além de proporcionar trocas de experiências entre professor/professor, aluno/aluno e professor/aluno.

A informática e a internet são importantíssimas para a educação, visto que facilitam as pesquisas e apóiam o desenvolvimento de trabalhos pedagógicos inseridos no cotidiano escolar. Em grande parte das escolas, são criados laboratórios de informática com o intuito de mostrar aos alunos como as tecnologias podem ajudálas no seu dia a dia, contribuindo para o desenvolvimento do capital intelectual e facilitando a realização de suas atividades (TAJRA, 2001).

Segundo Campbell (2009), para que haja a inclusão digital na educação não basta instalar computadores em escolas públicas, pois, em muitas delas, o uso dos computadores ainda não foi incorporado ao projeto pedagógico, permanecendo fechados em salas que só se abrem para aulas de informática. O computador deveria ser ferramenta para o trabalho docente, não somente para lançar notas e preparar material para aulas, mas sua utilização deveria ser mais explorada, pois muitos sabem até utilizar certos softwares, porém não sabem empregá-los em sua prática em sala de aula, utilizando o computador e a internet como meio para buscar informações e recebimento e envio de mensagens e documentos.

Segundo Weiss (2009, p. 133), existe uma forte necessidade de se entender as possibilidades e os limites desses suportes da informática, incluindo as questões éticas de sua utilização, para garantir uma boa mediação, pois o uso da informática tem de ser relevado com um precioso instrumental, não só nos diagnósticos psicopedagógicos, mas também no tratamento das dificuldades de aprendizagem esco- lar. Neste contexto, o computador pode ser utilizado como um auxiliar na reformulação de aprendizagem, diferenciando o brincar com joguinhos e outras práticas educacionais.

Campbell (2009) apresenta a ideia de que a política educacional deve ser formulada na busca de priorizar os recursos para se absorver e utilizar as tecnologias que ampliaram a visão e inteligência humana. Não se pode aceitar um ensino que desconsidere esta conjuntura, pois é necessário que haja uma pedagogia que incentive a aprendizagem personalizada a partir do interesse de cada um e, ao mesmo tempo, viabilize a aprendizagem coletiva em que o professor será cada vez mais um orientador indispensável, um coordenador de expedições em busca do saber coletivo.

No Brasil existem vários programas voltados à inclusão digital, aplicados dentro da educação, e, dentre eles, foi instituído um programa de alfabetização digital chamado MOVA digital, criado pela Secretaria Municipal de Educação de São Paulo em 2001, baseado na pedagogia do educador Paulo Freire (MENEZES, 2002).

\subsection{HISTÓRIA DA POLÍTICA DA INFORMÁ- TICA EDUCATIVA NO BRASIL}

A informática voltada para o século XXI traz impactos causados principalmente dentro da sociedade brasileira, com suas diversidades econômica, social e cultural, que contemplam elementos ricos para buscar novos caminhos que estimulem o Brasil a ser um país melhor.

Segundo Tajra (2001), o Brasil avançou nas políticas da informática, e o seu maior desafio foi fazer com que, através dos canais governamentais, os cidadãos pudessem se agregar e promover atuações para disseminar o uso das TICs, e, desta forma, pudessem contribuir para a inclusão social de todos os brasileiros, acabando com o analfabetismo digital. 
Para isso a autora faz um apanhado dos principais momentos vividos pela Política da Informática no Brasil:

Em 1965, o Ministério da Marinha brasileira tinha interesse em desenvolver um computador com knowhow próprio; Em 1971, o Ministério da Marinha, por intermédio do Grupo de Trabalho Especial - GTE - e o Ministério do Planejamento tomaram a decisão de construir um computador para as necessidades navais no Brasil; Em 1972, as questões importantes e exportações da Informática eram transferidas para a CAPRE - Coordenação de Atividades de Processamento Eletrônico, ligada ao Ministério do Planejamento; Em 1977, houve o primeiro confronto entre o Brasil e interesses estrangeiros, pela falta de uma definição explícita da reserva de mercado em relação aos mini e microcomputadores - IBM e Burroughs; Em 1979, as ações da CAPRE foram transferidas para a SEI (Secretaria Especial de Informática) ligada ao CSN (Conselho de Segurança Nacional). Esta decisão acarretou inúmeras discussões pelo fato de a CSN estar ligada às opressões da ditadura militar; Em 1984 é aprovada a Lei de Informática, a qual impôs restrições ao capital estrangeiro, tornou legal a aliança do Estado com o capital privado nacional. Essa lei tinha uma previsão para 8 anos, tempo estimado para que a indústria nacional alcançasse maturidade visando à competitividade internacional; Em 1985, faltam recursos humanos capacitados para o sistema de ciência e tecnologia. A partir daí, o governo passou a intensificar os investimentos na área de educação de $1^{\circ}$ e $2^{\circ}$ graus (p. 28).

O desígnio das políticas públicas é beneficiar a comunidade, tendo assim uma dimensão de suma relevância, pois estão intrinsecamente interligadas ao bem estar de uma determinada população. Estas políticas podem estar colaborando com o desenvolvimento cultural, educacional, voltadas à qualidade de vida dos indivíduos e, também, com a inclusão digital que proporciona aos beneficiários a oportunidade de estarem imersos neste novo universo que se configura como a era digital.

Em 1998 foi criado o documento Parâmetros Curriculares Nacionais - PCN, que se refere ao terceiro e quarto ciclos do ensino fundamental e trata da necessidade do uso das TICs na Educação, onde explicita que "a tecnologia deve ser utilizada para gerar situações de aprendizagem com maior qualidade - criar ambientes de aprendizagem em que a problematização, a atividade reflexiva, atitude crítica, capacidade decisória e autonomia sejam privilegiadas" (BRASIL, 1998, p.140).

Através da Portaria Interministerial (MC e MEC) no 122 , de 15 de maio de 2003: vigora a possibilidade de se alocar recurso adicional ao Programa Governo Eletrônico - Serviço de Atendimento ao Cidadão (Gesac), para prover as escolas públicas com conexão à internet.

O Decreto no 4.769, de 27 de junho de 2003: revoga a alínea b do inciso II do art. 70 do Plano Geral de Metas para a Universalização do Serviço Telefônico Fixo Comutado Prestado no Regime Público (PGMU). E o Decreto no 6.094, de 24 de abril de 2007: cria o Plano de Metas Compromisso Todos pela Educação, pela União Federal, em regime de colaboração com municípios, Distrito Federal e os estados, contando também com a participação das famílias e da comunidade, mediante programas e ações de assistência técnica e financeira, visando à mobilização social pela melhoria da qualidade da educação básica.

O Decreto no 6.300, de 12 de dezembro de 2007: amplia e especifica ainda mais as ações e objetivos do Programa Nacional de Informática na Educação (Pro- 
Info), como a formação de professores, a disponibilização de conteúdos educacionais, o provimento de infraestrutura para os laboratórios de informática, e assegura o suporte técnico e a manutenção dos equipamentos do ambiente tecnológico do Programa, findo o prazo de garantia da empresa fornecedora contratada. E o Decreto $\mathrm{n}^{0}$ 6.424, de 4 de abril de 2008: altera e acresce dispositivos ao Anexo do Decreto no 4.769, instituindo como beneficiários da banda larga escolas públicas e núcleos de tecnologia educacional (NTEs) estaduais e municipais.

O Decreto no 6.948, de 25 de agosto de 2009: institui o Comitê Gestor do Programa de Inclusão Digital (CGPID) e dá outras providências. O Decreto no 6.991, de 27 de outubro de 2009: institui o Programa Nacional de Apoio à Inclusão Digital nas Comunidades (Telecentros.BR), para desenvolver ações conjuntas entre órgãos do Governo Federal, estados, Distrito Federal, municípios e sociedade civil que possibilitem a oferta, a implantação e a manutenção, em larga escala, de telecentros. E em 2010 o Decreto no 7.175, de 12 de maio, institui o Programa Nacional de Banda Larga (PNBL); dispõe sobre remanejamento de cargos em comissão; altera o Anexo II do Decreto no 6.188, de 17 de agosto de 2007; altera e acresce dispositivos ao Decreto no 6.948, de 25 de agosto de 2009; e dá outras providências.

A Lei no 12.249 , de 11 de junho de 2010, institui o Regime Especial de Incentivos para o Desenvolvimento de Infraestrutura da Indústria Petrolífera nas Regiões Norte, Nordeste e Centro-Oeste (Repenec); cria o Programa um computador por aluno (Prouca) e institui o Regime Especial de Aquisição de Computadores para Uso Educacional (Recompe).

Várias foram as ações políticas que alicerçaram a educação e disponibilizaram meios para a inserção de computadores e internet dentro das escolas, favorecendo toda educação básica da rede pública, propendendo, através destas políticas, à melhoria da qualidade de ensino das escolas, sendo possível garantir aos alunos a ascensão do conhecimento através da informática, que é uma tecnologia bastante utilizada na sociedade moderna (TAJRA, 2001, p.13).

Assim é possível compreender que o papel das políticas públicas voltadas à exclusão digital é criar e socializar novas formas de utilização das tecnologias digitais nas escolas públicas brasileiras, para ampliar o processo de inclusão digital escolar e promover através delas o uso das TICs em caráter pedagógico.

\subsection{Preparação dos professores para A ERA DIGITAL}

Sendo a escola um local rico em diversidade, é possível afirmar que ela é o principal agente da mudança de paradigmas, pois proporcionam, aos profissionais envolvidos neste processo, atividades que despertam o respeito ao próximo e suas limitações, ressaltando suas potencialidades e contribuições oferecidas dentro de seus limites.

Abordar questões como cidadania, inclusão digital e democracia são paradigmas traçados pelas instituições escolares, respaldadas pelas legislações, que visam a formação de uma sociedade com oportunidades igualitárias.

A introdução dos microcomputadores na sala de aula ou na escola, através de laboratórios de informática, pode representar uma possibilidade mais eficaz de lidar com alguns tópicos do ensino. Porém, para o melhor proveito desse recurso tecnológico, é necessário voltar as atenções à aprendizagem dos professores, para que eles possam fazer modificações importantes e interessantes no processo de aprendizagem de seus alunos.

Nesta perspectiva, a formação do processo é fundamental, e o Governo, 
através da Lei no 12.249 , de 11 de junho de 2010, disponibilizou um Computador Portátil para Professores. Este projeto deu continuidade ao Projeto Cidadão Conectado - Computador para Todos, o Governo Federal desenvolveu uma ação dirigida principalmente aos professores do ensino continuado das instituições credenciadas ao MEC, visando facilitar a aquisição de computadores portáteis, criando mecanismos para isso, com baixo custo e com empréstimos em condições diferenciadas para professores das instituições públicas e privadas, credenciadas ao MEC, além de providenciar recursos voltados à formação continuada, para contribuir com o aperfeiçoamento da capacidade de produção e de formação pedagógica pela interação com as TICs.

Tajra (2001) afirma que existe uma grande necessidade de aprimorar os conhecimentos do professor para com os recursos disponíveis de programas que desenvolvam atividades de ensino, preparando-o para realizar uma aula dinâmica, criativa e segura.

Para Kenski (2007), a utilização do computador na educação tem sentido e é totalmente benéfica, na medida em que os professores o concebem como uma ferramenta de auxílio às suas atividades didático-pedagógicas, e passam a aceitá-lo como instrumento de planejamento e realização de projetos interdisciplinares, que pode exercer a função de motivar e ao mesmo tempo desafiar os alunos, tornando-se uma nova prática pedagógica dentro do processo ensino-aprendizagem, como uma forma inovadora, dinâmica, participativa e interativa de aplicar atividades contextualizadas na aquisição de conhecimentos.

Através da política voltada à inclusão dos professore neste contexto tecnológico, o Governo implementou alguns programas como: Proinfo - Programa Nacional de Informática na Educação; ePROINFO - Ambiente Virtual de Aprendi- zagem (AVA); UAB- Universidade Aberta do Brasil; RIVED - Rede Interativa Virtual; PAPED - Programa de Apoio à Pesquisa em Educação a distância; Webeduc; Portal Domínio Público; Educação Superior a Distância, entre outros (TEIXEIRA, 2010).

Alguns desses programas se caracterizam como um ambiente colaborativo baseado em tecnologia web, que permite ao usuário administrar e desenvolver diversos tipos de ações, como cursos a distância, complemento a cursos presenciais, projetos de pesquisa, projetos colaborativos e outras formas de apoio ao processo ensino-aprendizagem (TAJRA, 2001).

Pretto (2005) analisa que os professores que possuem uma formação continuada estabelecem um maior entrosamento com as TICs, e reconhecem a importância da inclusão digital, visto que eles também se incluem nesta parcela da população que não tem acesso às facilidades e ao conhecimento tecnológico do mundo contemporâneo, não dispondo dos benefícios proporcionados pela cultura digital.

Os professores em formação continuada podem desempenhar funções de um forte articulador dos processos inovadores, pedagógicos e tecnológicos, auxiliando na elaboração de projetos, através de boas sugestões, informando sobre as inovações, e sua utilização, e podem oferecer a seus alunos, estímulo, dinamização e valorização dos trabalhos realizados, através de blogs ou em fóruns e redes sociais, dando e tendo a conscientização de que, através desses recursos, eles podem se sentir mais livres para ousar e criar.

\section{CONSIDERAÇÕES FINAIS}

O grande desafio da educação é transformar os direitos idealizados de todos os cidadãos em realidade e o benefício da inclusão digital na educação como requisito para exercício da cidadania. Pode- 
mos ver que, em meio a tantas tecnologias disseminadas nesta era tecnológica, temos a necessidade de nos adequar a esta realidade e aprender a usufruir de seus benefícios como ter acesso a jornais, realizar visitas virtuais a museus e a outros lugares fora de seu país, pesquisas em bibliotecas, conversas com parentes e amigos através das redes sociais, compras diversas, entre outras atividades. Hoje a internet vem a ser a principal ferramenta de informação que conecta o mundo.

Assim, aqueles que não possuem acesso a ela ou não sabem trabalhar com esta ferramenta, interpretando suas codificações e usufruindo dessas tecnologias, são considerados analfabetos digitais.

O Governo Federal brasileiro vem, desde a década de 80 , desenvolvendo e investindo em programas que visam à inclusão digital dos cidadãos, voltando suas atenções àqueles de baixa renda. 0 trabalho buscou refletir sobre as formas propostas para a erradicação desse analfabetismo, numa visão de dentro da escola.

A implementação de laboratórios de informática, dentro dos contextos escolares, vem a favorecer o direito à igualdade de oportunidades, visando o exercício da cidadania, além de resgatar os excluídos em plena era da informática digital, através dos programas e políticas públicas.

Apesar de existirem bons programas e políticas públicas voltadas à inclusão digital na educação, no meio do caminho, houve tropeços e houve esbarrões com as políticas municipais que, a cada vez que eram mudadas, desfavoreciam o que já havia sido feito, tornando o acesso de muitas escolas desprivilegiadas por sua estrutura física e seu local ficarem à margem desta inclusão.

A exclusão digital é uma das causas do analfabetismo tecnológico e, em concordância a ela, temos o agravante da exclusão social, que vem, de acordo com a realidade, mostrando que ainda existem pessoas que desconhecem as tecnologias, pessoas que não têm celular, não possuem computadores com acesso a internet e, desta forma sutil, vem havendo a ampliação das desigualdades, o que é uma violência velada, pois constitucionalmente somos todos iguais e temos os mesmos direitos, porém, não temos igualdade de condições.

Percebe-se que a utilização das tecnologias e da informação, por ela mediada, se torna importante para o desenvolvimento econômico e social do país e a escola pode se tornar mediadora desse recurso, partindo do princípio da inclusão digital. Sendo assim, abre-se novas oportunidades de melhorar a educação tornando-a de qualidade e para todos.

\section{REFERÊNCIAS BIBLIOGRÁFICAS}

BRASIL. Constituição da República Federativa do Brasil. Brasília: Senado, 1988.

. Lei no. 9.394 de 20 de dezembro de 1996. Lei de Diretrizes e Bases da Educação Nacional.

CAMPBELL, Selma Inês. Múltiplas faces da Inclusão. Rio de Janeiro: Wak Ed., 2009.

JUNIOR, João de Pontes. Alfabetização Digital: proposição de parâmetros metodológicos para capacitação em competência informacional. Dissertação de Mestrado, Pontifícia Universidade Católica de Campinas, 2009.

KENSKI, Vani Moreira. Educação e Tecnologias: O novo ritmo da informação. ISBN 978 - 85 - 308 - 0828 - 0. Campinas, São Paulo: Papirus, 2007.

MENEZES, Ebenezer Takuno de; SANTOS, Thais Helena dos. "Analfabetismo tecnológico" (verbete). Dicionário Interativo da 
Educação Brasileira - EducaBrasil. São Paulo: Midiamix Editora, 2002. Disponível em: http://www.educabrasil.com.br/eb/ $\mathrm{dic} /$ dicionario. asp?id=474. Acessado em $18 / 11 / 2013$.

PRETTO, Nelson de Luca (org.). Tecnologias e novas educações. Salvador: EDUFBA, 2005 (Coleção Educação, Comunicação e Tecnologias, v. 1). PRETTO, Nelson de Luca Entrevista para o Programa Salto para o Futuro. Série Cibercultura: o que muda na Educação.

SILVEIRA, Sérgio Amadeu. Exclusão Digital: a miséria na era da informação. São Paulo: Fundação Perseu Abramo, 2005.

TARJA, Sanmya Feitosa. Informática na Educação: Novas ferramentas pedagógicas para o professor da atualidade. 3. Ed. Rev., atual. e amp. - São Paulo: Érica, 2001.

TEIXEIRA, Adriano Canabarro. Inclusão digital: novas perspectivas para a informática educativa. ISBN 978-85-7429-851-1 Ijuí: Ed. Unijuí, 2010.

WEISS, Maria Lúcia Lemme. Vencendo as dificuldades de aprendizagem escolar. Rio de Janeiro: Wak Ed., 2009. 